\title{
The DCC gene product in cellular differentiation and colorectal tumorigenesis
}

\author{
Lora Hedrick, ${ }^{1,2}$ Kathleen R. Cho, ${ }^{1,2}$ Eric R. Fearon, ${ }^{3}$ Tzyy-Choou Wu, ${ }^{1}$ Kenneth W. Kinzler, ${ }^{2}$ \\ and Bert Vogelstein ${ }^{2}$ \\ ${ }^{1}$ Department of Pathology, The Johns Hopkins University School of Medicine, Baltimore, Maryland 21205 USA; ${ }^{2}$ Molecular \\ Genetics Laboratory, The Johns Hopkins Oncology Center, Baltimore, Maryland 21231 USA; ${ }^{3}$ Department of Pathology, \\ Boyer Center for Molecular Medicine, Yale University School of Medicine, New Haven, Connecticut 06536 USA
}

\begin{abstract}
The analysis of human colorectal tumors has revealed frequent loss of heterozygosity (LOH) of the long arm of chromosome 18. A novel gene, DCC (deleted in colorectal cancer), located within the region of LOH on chromosome $18 \mathrm{q}$ was identified and has been implicated as a tumor suppressor gene. We have now shown that $D C C$ encodes a membrane-bound protein of the immunoglobulin-CAM family, as demonstrated by cell-surface labeling, immunohistochemical analysis, and sequencing of cDNA clones. The DCC protein was found in axons of the central and peripheral nervous system and in differentiated cell types of the intestine. Colorectal tumors that lost their capacity to differentiate into mucus producing cells uniformly lacked DCC expression and loss of a chromosome 18q allele was often accompanied by loss of DCC expression in colon tumors. These results provide evidence that $D C C$ encodes a cell surface-localized protein and emphasize the inverse relationship between differentiation and tumorigenesis.
\end{abstract}

[Key Words: DCC; tumorigenesis; differentiation; immunohistochemistry]

Received February 10, 1994; revised version accepted March 31, 1994.

The importance of tumor suppressor genes in the etiology of the common forms of human cancer is becoming increasingly more apparent (Marshall 1991). Tumor suppressor genes are targets of allelic losses of heterozygosity in cancer cells. The loss of one allele of a tumor suppressor gene is often accompanied by a mutation in the remaining allele. The products of tumor suppressor genes normally function to regulate cell growth and differentiation, and their loss of function contributes to the neoplastic phenotype. Although only seven candidate tumor suppressor genes have been cloned, several more have been predicted to exist and play a role in the development and progression of various tumor types. The proteins encoded by these genes are likely to vary substantially in their biochemical properties, as cellular growth is known to be controlled by numerous mechanisms operative throughout the cell.

Heterozygosity of the long arm of chromosome 18 is lost in $\sim 75 \%$ of colorectal cancers (CRCs) as assessed by both cytogenetic (Muleris et al. 1987; Boman et al. 1988) and molecular genetic methods (Monpezat et al. 1988; Vogelstein et al. 1988). This prompted a search for a gene within the commonly lost region of chromosome $18 \mathrm{q}$ that was the target of such losses. A previously undescribed gene, $D C C$, was found within the lost region and shown to be altered by somatic mutation in several colorectal cancers (Fearon et al. 1990; Cho et al. 1994).
Most CRCs analyzed had low or undetectable levels of DCC mRNA compared with normal colonic mucosa. Subsequent studies confirmed that DCC allelic loss and reduction of the expression of its $\mathrm{mRNA}$ are common in CRC and also occur in other tumor types (Hohne et al. 1992; Uchino et al. 1992; Gao et al. 1993; Klingelhutz et al. 1993; Porfiri et al. 1993). A partial cDNA clone, encoding the amino terminus of DCC, has been described and encodes a protein with significant homology to the immunoglobulin gene superfamily of cell-surface glycoproteins (Fearon et al. 1990).

$D C C$ thus represents a candidate tumor suppressor gene whose product is predicted to lie within the plasma membrane. To test these predictions, a DCC cDNA encoding a complete open reading frame (ORF) has now been identified. The expression of DCC protein was assessed at the tissue and cellular levels using antibodies generated against DCC fusion proteins. Expression studies showed a remarkable relationship between DCC expression, cellular differentiation, and tumorigenesis.

Results

Cloning of DCC $c D N A$

DCC was initially identified through overlapping cDNA clones encompassing a single ORF of $2250 \mathrm{bp}$ (Fearon et al. 1990). This sequence contained a methionine codon 
with surrounding nucleotides favorable for translation initiation, in-frame stop codons upstream, but no downstream stop codons. The remainder of the ORF was established through further screening of human fetal and adult brain cDNA libraries, chosen because of the relatively high level of expression of $D C C$ in brain compared with other tissues. Several rounds of cDNA walking resulted in a further series of overlapping clones that encompassed an ORF of $4341 \mathrm{bp}$. The ORF predicted a 1447-amino-acid protein with features of a transmembrane molecule (Fig. 1A). The first 25 amino acids following the initiating methionine had a hydrophobic composition typical of signal sequences found in membrane-associated proteins. The putative signal sequence was followed by 382 amino acids defining four regions with homology to immunoglobulin-like C2 domains. The immunoglobulin-like domains were followed by six fibronectin type III repeats (Fig. 1B). The tandem immunoglobulin-like and fibronectin domains are characteristic of members of the immunoglobulin superfamily, including neural cell adhesion molecules (N-CAMs) and other cell-surface glycoproteins (Edelman 1988). Following the fibronectin repeats, there was a highly hydrophobic transmembrane-spanning region of 25 amino acids bordered by basic residues, followed by a stretch of 325 amino acids. The putative cytoplasmic domain did not show homology to any gene recorded in standard data banks. A schematic diagram of the DCC protein is shown in Figure 1C.

\section{Detection and subcellular localization of the DCC gene product in cultured cells}

Two rabbit polyclonal antibodies were raised against fusion proteins containing unique sequences of the $D C C$ cDNA. One antibody was raised to a portion of the extracellular domain (EXDCC, amino acids 198-413), and the other included the entire intracytoplasmic domain (INDCC, amino acids 1104-1447). An initial screen of 32 cell lines by immunoprecipitation and Western blot analysis revealed only one positive cell line, derived from a testicular nonseminomatous germ cell tumor, called 577MF. These results correlated with RNA expression studies. A total of 12 cell lines and normal tissues were assayed by RNase protection. 577MF was the only cell line, and rat brain the only tissue in which DCC expression was detected (Table 1). DCC RNA was, however, detectable by the more sensitive reverse transcription polymerase chain reaction (RT-PCR) assay in most of the other cell lines and tissues (Table 1). Both polyclonal anti-DCC antibodies precipitated a protein of $\sim 170 \mathrm{kD}$ apparent molecular mass from metabolically labeled 577MF cell lysates (Fig. 2A). As the predicted molecular mass of DCC is $153 \mathrm{kD}$, the slower mobility of the immunoprecipitated protein is likely attributable to post-translational modification, perhaps by glycosylation at potential $\mathrm{N}$-linked glycosylation sites identified by sequence analysis in the extracellular domain. Furthermore, immunoprecipitation of lysates from 577MF cells labeled by cell-surface iodination demonstrated that the protein detected by the antibodies was present on the cell surface (Fig. 2B). To further evaluate subcellular localization, $\mathrm{CHO}$ cells were transfected with a DCC expression vector. Western blot and immunoprecipitation analysis showed that the transfected, but not the parental, cells expressed a protein with an apparent molecular mass of $\sim 180 \mathrm{kD}$ (Fig. 3A). The difference in the molecular mass of endogenous DCC in 577MF and exogenous DCC is likely attributable to alternative splicing. RNase protection assays, using a probe corresponding to cDNA nucleotides 2031-2749, revealed differences in the size of the protected bands in 577MF cells when compared with those seen in brain (data not shown). Human brain was the source of the cDNA, and by Western blot analysis the protein product of brain, like the exogenous product, migrates at $\sim 180 \mathrm{kD}$. Immunocytochemical analysis of the same DCC-transfected $\mathrm{CHO}$ clone showed staining consistent with membrane localization with increased intensity at sites of cell-cell contact (Fig. 3C). These studies provide strong evidence that the detected protein is the product of the DCC gene and that DCC is a cell-surface protein.

\section{Expression of the DCC protein in normal tissues}

Attempts to detect DCC expression in tissues by Western blot analysis were largely unsuccessful. The only tissue in which a positive signal was observed was both human and rat brain, in which a very faint band of $\sim 180$ $\mathrm{kD}$ was present. We suspected that DCC expression might be limited to specific cell types or subcellular regions (like the plasma membrane) within tissues, making immunohistochemical analysis potentially more sensitive than techniques relying on whole tissue homogenates. Immunohistochemical analysis was first performed on tissues from the central nervous system, based on the previously mentioned RNA expression studies. Frozen sections of human spinal cord revealed staining primarily in axonal processes. Staining was observed in both myelinated and nonmyelinated fibers at several levels of the spinal cord and brain stem (Fig. 4B). Subsequent examination of brain revealed a similar specificity, with pronounced staining limited to axons predominantly in the white matter. Some nerve cell bodies were also stained, particularly Purkinje cells in the cerebellum (Fig. 4C). The expression of DCC in Purkinje cells was verified by in situ hybridization using $D C C$ antisense RNA probes (Fig. 4D).

Several other tissues were assessed for DCC immunoreactivity. Although faint staining of occasional cells was observed in several tissues (including bladder, small bowel, and endometrium), the most pronounced staining was found in the colon. In colon, only cells with goblet cell morphology reacted with the antibody (Fig. 5B). Colonic epithelium contains two major differentiated cell types: absorptive cells responsible for fluid and electrolyte transport (enterocytes), and cells that produce and secrete mucins (goblet cells). The goblet cells represent $20-30 \%$ of the epithelium and are conspicuous because of their large apical intracellular mucin accumulation. 
Hedrick et al.

A

1 MENSLRCVWVPKLAFVLFGASLLSAHLQVTGFQI KAFTALRFLSEPSDAVTMRGGNVLLDCSAESDRGVPVI KWKKDGIHLALGMDERKQQLSNGSLLIQ

101 NILHSRHHKPDEGLYQCEASLGDSGSI I SRTAKVAVAGPLRFLSQTESVTAFMGDTVLLKCEVIGEPMPTIHWQKNQQDLTPI PGDSRVVVLPSGALIS

201 RLQPGDIGIYRCSARNPASSRTGNEAEVRI LSDPGLHRQLYFLQRPSNVVAI EGKDAVLECCVSGYPPPSFTWLRGEEVIQLRSKKYSLLGGSNLLISNV

301 TDDDSGMYTCVVTYKNENISASAELTVLVPPWFLNHPSNLYAYESMDI EFECTVSGKPVPTVNWMKNGDVVI PSDYFQI VGGSNLRI LGVVKSDEGFYQC

401 VAENEAGNAQTSAQLIVPKPAI PSSSVLPSAPRDVVPVLVSSRFVRLSWRPPAEAKGNIQTFTVFFSREGDNRERALNTTQPGSLQLTVGNLKPEAMYTF

501 RVVAYNEWGPGESSQPI KVATQPELQVPGPVENLQAVSTSPTS I I ITWEP PAYANGPVQGYRLFCTEVST GKEQNI EVDGLSYKLEGLKKFTEYSLRFLA

601 YNRYGPGVSTDDI TVVTLSDVPSAP PQNVSLEVVNSRSI IVSWLPPPSGTQNGFI TGYKI RHRKTTRRGEMETLEPNNLWYLFTGLEKGSQYSFQVSAMT

701 WNGTGPPSNWYTAETPENDLDESQVPDQPSSLHVRPQTNCI IMSWTPPLNPNI VVRGYI I GYGVGSPYAETVRVDS KQRYYS I ERLESSSHYVI SLKAFN

801 NAGEGVPLYESATTRSITDPTDPVDYYPLLDDFPTSVPDLST PML,PPVGVQAVALTHDAVRVSWADNSVPKNQKTSEVRLYTVRWRTSFSASAKYKSEDT

901 TSLSYTATGLKPNTMYEFSVMVTKNRRSSTWSMTAHATTYEAAPTSAPKDFTVI TREGKPRAVI VSWQP PLEANGKI TAY I LFYTLDKNI P I DDWIMETI

1001 SGDRLTHQIMDLNLDTMYYFRIQARNSKGVGPLSDPILFRTLKVEHPDKMANDQGRHGDGGYWPVDTNLI DRSTLNEPPI GQMHP PHGSVTPQKNSNLVV

1101 IIVVTVGVITVLVVVIVAVICTRRSSAQQRKKRATHSAGKRKGSQKDLRPPDLWI HHEEMEMKN IEKPSGTDPAGRDSP IQSCQDLTPVSHSQSETQLGS

1201 KSTSHSGQDTEEAGSSMSTLERSLAARRAPRAKLMI PMDAQSNNPAVVSAI PVPTLESAQY PGI LPS PTCGY PHPQFTLRPVPFPTLSVDRGFGAGRSQS

1301 VSEGPT TQQP PML PPSQPEHSSSEEAPSRT I PTACVRPTHPLRSFANPLLLPPPMSA I E PKVPYTPLLSQPGPTLPKTHVKTASLGLAGKARSPLLPVSVP

1401 TAPEVSEESHKPTEDSANVYEQDDLSE.QMASLEGLMKQLNAITGSAF

B

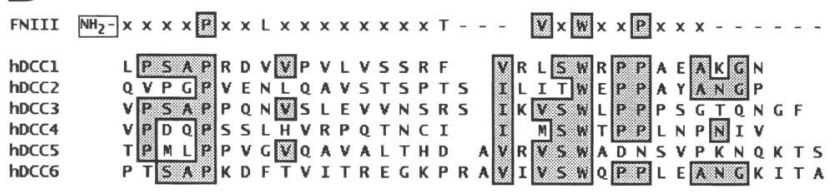

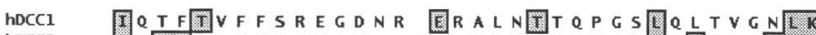

hDCC2 VOGYRLFCTEVST G KEQNIEVDGLSWKLEGI

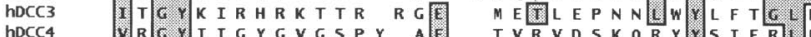

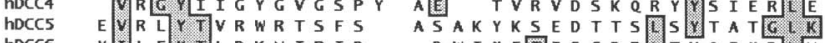

YLFITLOKIPID DWIME团ISGDR THQIMDLUN

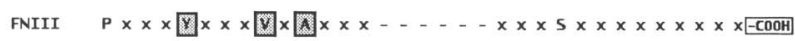

hocc1 P EA

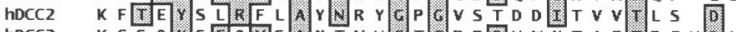

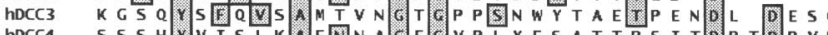

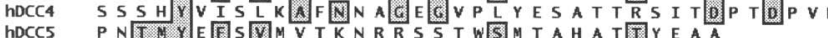

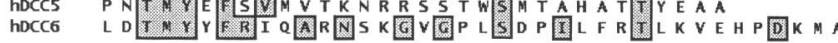

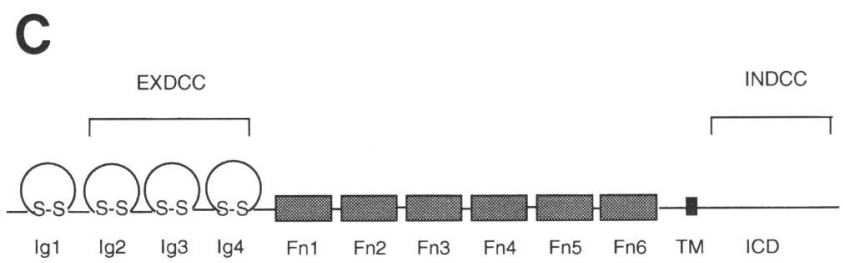

Figure 1. Predicted amino acid sequence of DCC and comparison of fibronectin type III repeats. (A) The 1447 amino acid sequence predicted by the $4341 D C C$ ORF deduced from human fetal and adult brain cDNA clones (EMBL Data Library accession no. X76132). The putative signal sequence is underlined, and the potential transmembrane spanning sequence is designated in bold and underlined. The proposed extracellular portion of the sequence contains four regions that show homology to immunoglobulin C2-like domains and six regions with homology to fibronectin type III repeats. The 325-amino-acid cytoplasmic domain does not show homology to any sequences in current data banks. (B) Alignment of the sequences of the six fibronectin type III (FNIII) domains of DCC with one another and with a fibronectin type III domain consensus sequence. A consensus fibronectin type III domain sequence has been obtained and described by Patthy, following comparison of the fibronectin III domains present in fibronectin, cytotactin, contactin, L1, N-CAM, fasciclin II, leukocyte common antigen-related protein LAR 1, and twitchin (Patthy 1990). This fibronectin III consensus sequence is shown in single-letter amino acid code from amino $\left(\mathrm{NH}_{2}\right)$ to carboxy $(\mathrm{COOH})$ termini. A consensus amino acid is indicated if the same amino acid was present at a position in at least $75 \%$ of the type III modules studied. $\mathrm{X}$ indicates that there was no consensus amino acid at a particular position. Dashes indicate regions/positions tolerant to gaps in the sequence. The sequences of the six fibronectin III domains of human DCC (hDCC1-hDCC6) were manually aligned with the fibronectin III consensus sequence to give the greatest overall match. Where three or more of the DCC fibronectin III domain sequences share the same amino acid at a particular position, the amino acids are shaded. Where the shaded amino acids of the DCC fibronectin III domain sequences matched the consensus fibronectin III domain sequence, the amino acid in the consensus sequence is also shaded. (C) A schematic diagram of the DCC protein demonstrates the arrangement of the different domains and indicates the regions of DCC used to generate the polyclonal antibodies. (EXDCC) Extracellular antibody; (INDCC) intracytoplasmic antibody. The remaining abbreviations for the schematic diagram are as follows: (Ig) Immunoglobulin-like C2 domains; (Fn) fibronectin type III repeats; (TM) transmembrane domain; (ICD) intracytoplasmic domain.

The expression of DCC within the goblet cells was concentrated at the basolateral borders of the cells and in the supranuclear cytoplasmic space (Fig. 5E,F). The Golgi apparatus is located in this supranuclear space, and it is possible that the DCC signal in this area represents nascent protein.
Preimmune serum did not stain any of the reactive cells described above (Fig. 5A). As a further control for specificity, the analyses were performed in the presence of soluble fusion proteins as competitors. DCC fusion protein at the same concentration as the DCC antibody completely blocked the signal detected by the antibody 
Table 1. DCC protein and $m R N A$ expression in selected cell lines and tissues

\begin{tabular}{lcccccc}
\hline $\begin{array}{l}\text { Cell lines } \\
\text { and } \\
\text { tissues }\end{array}$ & IP & Western & IHC & Northern & RNase & PCR \\
\hline 577MF & + & + & N.D. & + & + & + \\
SW480 & - & - & N.D. & - & - & - \\
RKO & - & N.D. & N.D. & - & - & + \\
COS-7 & - & - & N.D. & N.D. & - & N.D. \\
CHO & - & - & - & N.D. & - & N.D. \\
CHO-T & + & + & + & N.D. & N.D. & N.D. \\
Brain & N.D. & + & + & + & + & + \\
Colon & N.D. & - & + & - & - & + \\
\hline
\end{tabular}

The qualitative levels of DCC expression are represented by various assays in selected cell lines and tissues. The assays for DCC protein include immunoprecipitation (IP), Western blot, and immunohistochemistry (IHC). The assays for mRNA include Northern blot, RNase protection (RNase), and reverse transcriptase polymerase chain reaction (RT-PCR). (N.D.) Assays not done on the individual cell lines and tissues. The cell lines displayed are 577MF (testicular nonseminomatous germ cell tumor), SW480 and RKO (human colorectal carcinoma), COS-7 (SV40-transformed African green monkey kidney), CHO |Chinese hamster ovary), and CHO-T (DCC-transfected CHO clone). All cell lines, with the exception of 577MF and CHO-T, are available through the American Type Culture Collection (ATCC). The tissues shown are human brain (cerebral cortex) and normal colonic mucosa.

in the goblet cells, whereas an irrelevant fusion protein ( $\left.\mathrm{His}_{6} \mathrm{myc}\right)$, even at fivefold the antibody concentration, failed to reduce the signal (Fig. 5C,D).

$D C C$ expression was also examined at the RNA level in normal colonic tissue using in situ hybridization. The general expression pattern of $D C C$ detected by in situ hybridization (Fig. 6) was identical to that detected by immunohistochemistry. The intensity of the signal was significantly greater in the epithelium of the neck and base of the crypts when compared with the epithelial cells lining the luminal surface (Fig. 6B,D). This pattern of expression correlates with the location of goblet cells within the crypt, which are found predominantly in the neck and base and are much less prevalent on the luminal surface. At high magnification (Fig. 6D) it is possible to discern that expression is localized primarily in goblet cells.

\section{Expression of DCC in colorectal tumors}

Immunohistochemistry was then used to investigate DCC protein expression in various tumors of the colorectum. We first examined three hyperplastic polyps. These tumors, as their name implies, consist of hyperproliferating cells that are not neoplastic. They retain a relatively normal architectural pattern and some features indicative of cellular differentiation (Fig. 7A). Although some epidemiological studies have suggested an association of hyperplastic polyps with colorectal cancer, there is little evidence that they are precursors to cancer. Relatively intense staining was observed in all of the epithelial cells within these polyps, not just the goblet cells, with the anti-DCC antibody (Fig. 7B). In addition, the staining within each cell had a different pattern than that observed in the goblet cells of the normal colonic epithelium. In the cells of the hyperplastic polyp, the staining was not confined to the basolateral regions but appeared to be dispersed over the entire cell. Normal epithelial cells adjacent to the polyps showed less intense staining with the expected distribution of DCC confined only to the goblet cells. Thus, DCC expression was increased rather than decreased in these non-neoplastic but proliferative and differentiating cells.

We then examined five adenomatous polyps, generally considered to be direct precursors of colorectal cancers. Early and intermediate stage adenomas retained expression of DCC in a largely normal pattern, limited to goblet cells. Two late adenomas with significant dysplasia revealed undetectable levels of DCC protein, with complete absence of staining in the neoplastic epithelium (Fig. 7C,D). Six invasive colorectal carcinomas were subsequently stained. Four of the carcinomas completely lacked detectable DCC staining (Fig. 7E,F) while two of the carcinomas stained intensely for DCC (Fig. 7G,H). The relationship between DCC expression and cells with mucin producing differentiation in the various colonic tumors was striking. Alcian blue (AB), a histochemical stain that specifically stains intestinal mucins, was used to counterstain several of the tissue sections

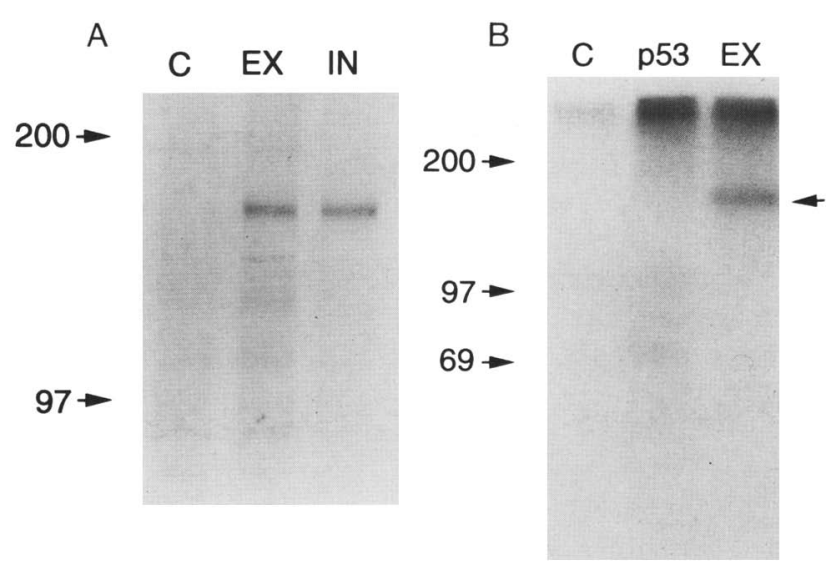

Figure 2. Immunoprecipitation of DCC from the cell line $577 \mathrm{MF}$. (A) 577MF cells were metabolically labeled with $\left.{ }^{35} \mathrm{~S}\right]$ methionine and $20 \times 10^{6} \mathrm{cpm}$ of precleared lysate was immunoprecipitated with specific antibody. (Lane 1) $10 \mathrm{ng} / \mu \mathrm{l} \mathrm{of}$ normal rabbit immunoglobulin as a control; (lane 2) $2 \mathrm{ng} / \mu \mathrm{l}$ of affinity-purified anti-EXDCC rabbit polyclonal antibody; and (lane 3) $2 \mathrm{ng} / \mu \mathrm{l}$ of affinity-purified anti-INDCC rabbit polyclonal antibody. (B) $577 \mathrm{MF}$ cells were also labeled with ${ }^{125} \mathrm{I}$ by a lactoperoxidase method to label only cell-surface proteins. (Lane 1) $10 \mathrm{ng} / \mu \mathrm{l}$ of normal rabbit immunoglobulin; (lane 2) 20 $\mathrm{ng} / \mu \mathrm{l}$ of anti-p53 mouse monoclonal antibodies (Oncogene Science) to rule out labeling of proteins not expressed on the cell surface; (lane 3) $2 \mathrm{ng} / \mu \mathrm{l}$ of affinity-purified anti-EXDCC rabbit polyclonal antibody. The arrow (right) indicates the iodinated DCC gene product. 


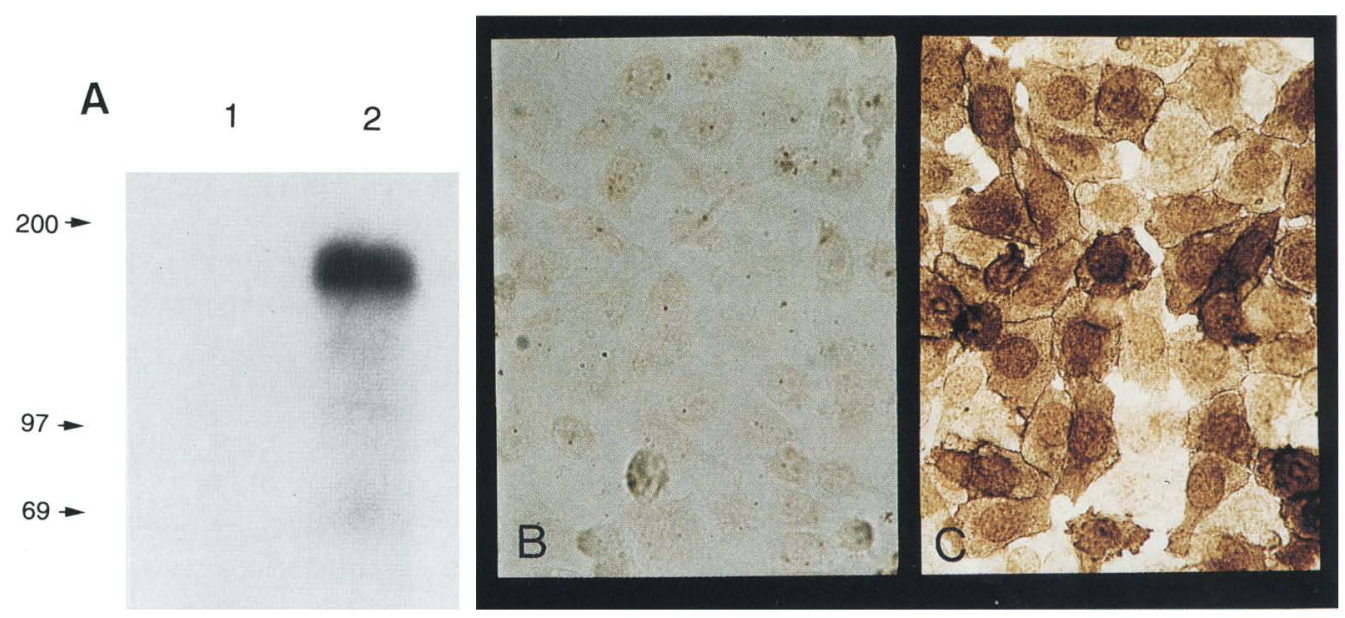

Figure 3. Western blot and immunocytochemistry of DCC-transfected CHO clone. $(A \mid$ Western blot analysis of total cellular protein $(100 \mu \mathrm{g})$ for expression of DCC in transfected CHO cells using anti-EXDCC rabbit polyclonal antibody. (Lane 1) Untransfected CHO cells; (lane 2) DCC-transfected CHO clone (CHO-2). Immunocytochemistry of the CHO-2 clone at $80 \%$ confluency using $2 \mathrm{ng} / \mu \mathrm{l}$ of anti-INDCC rabbit polyclonal antibody $(C)$ demonstrating cell-surface type staining with increased intensity at sites of cell-cell contact. $(B)$ The normal IgG control at $10 \mathrm{ng} / \mu \mathrm{l}$.

described above. Colocalization of $\mathrm{AB}$ staining cells and DCC reactivity was readily apparent in the normal colon (Fig. 5F). In hyperplastic polyps, increased AB staining was associated with elevated $D C C$ expression $(A B$ data not shown). In adenomatous polyps and cancers, DCC reactivity precisely correlated with the $\mathrm{AB}$ staining. Most colorectal cancers were moderately to poorly differentiated, exhibiting low or absent $\mathrm{AB}$ staining and focal or no DCC antibody reactivity. DCC reactivity was seen focally in several of the carcinomas, and its presence correlated with focal areas that also stained with $\mathrm{AB}$. This finding is consistent with the notion that DCC expression may play a role in mucinous differentiation.

The two DCC-positive carcinomas were found by $A B$ staining to fall into a class of carcinomas referred to as mucinous carcinomas, an uncommon type of CRC that produces abundant mucus. The results, in toto, suggested that most colorectal cancers lost DCC expression concomitant with loss of differentiation toward the mucin-producing pathway, but occasionally this loss did not occur. To further evaluate this issue, we retrospectively analyzed 49 cases of colorectal cancers for loss of $D C C$ alleles and histologic phenotype. Seven mucinous tumors were identified in these 49 cases, and in only 1 of the 7 was there evidence of $D C C$ loss. In contrast, in the 42 nonmucinous tumors, $D C C$ loss of heterozygosity (LOH) was observed in $34\left(P=0.0002, x^{2}\right)$. These results suggest that there are at least two colorectal tumorigenesis pathways: one that is associated with $D C C$ loss and the failure to differentiate toward mucin-producing cells, and the less common mucinous type unassociated with $D C C$ alteration.

\section{Discussion}

The mechanisms by which the products of tumor suppressor genes normally control cell growth remain little understood. Early studies on tumor suppressor genes suggested that their gene products may be involved in preventing cellular proliferation possibly through directly inhibiting DNA replication or indirectly through regulating the transcription of other genes involved in controlling the cell cycle. However, it is likely that tumor suppressor genes will be identified that encode proteins involved in a wide variety of normal cellular functions that must be overcome during tumorigenesis. One such function, for which there is experimental and empirical support, is terminal differentiation. The fact that terminal differentiation is often associated with a restricted number of subsequent cellular divisions emphasizes the inverse relationship between differentiation and neoplastic transformation. Previous studies have documented differences in gene expression between normal and transformed cells, with transformed cells often lacking markers associated with the differentiated phenotype. Furthermore, experimental evidence has shown that fusion of normal cells to transformed cells can, when injected into nude mice, cause the formation of tumors that show features indicative of differentiation (Peehl and Stanbridge 1982). More recently, molecular studies have revealed that the prototype tumor suppressor protein $\mathrm{Rb}$ may be involved in the control of cellular differentiation (Gu et al. 1993).

The immunohistochemical analysis reported here demonstrates DCC expression in mature, nondividing cell types in several tissues. In the peripheral and central nervous system DCC expression is limited to neurons. Neurons are regarded as terminally differentiated, nonreplicating cells. Several recent studies have demonstrated a functional role for DCC in the differentiation of rat PC-12 cells in vitro. PC-12 cells are derived from a rat pheochromocytoma and, when treated with nerve growth factor (NGF) in vitro, cease division and undergo a morphological change, visualized as the extension of 

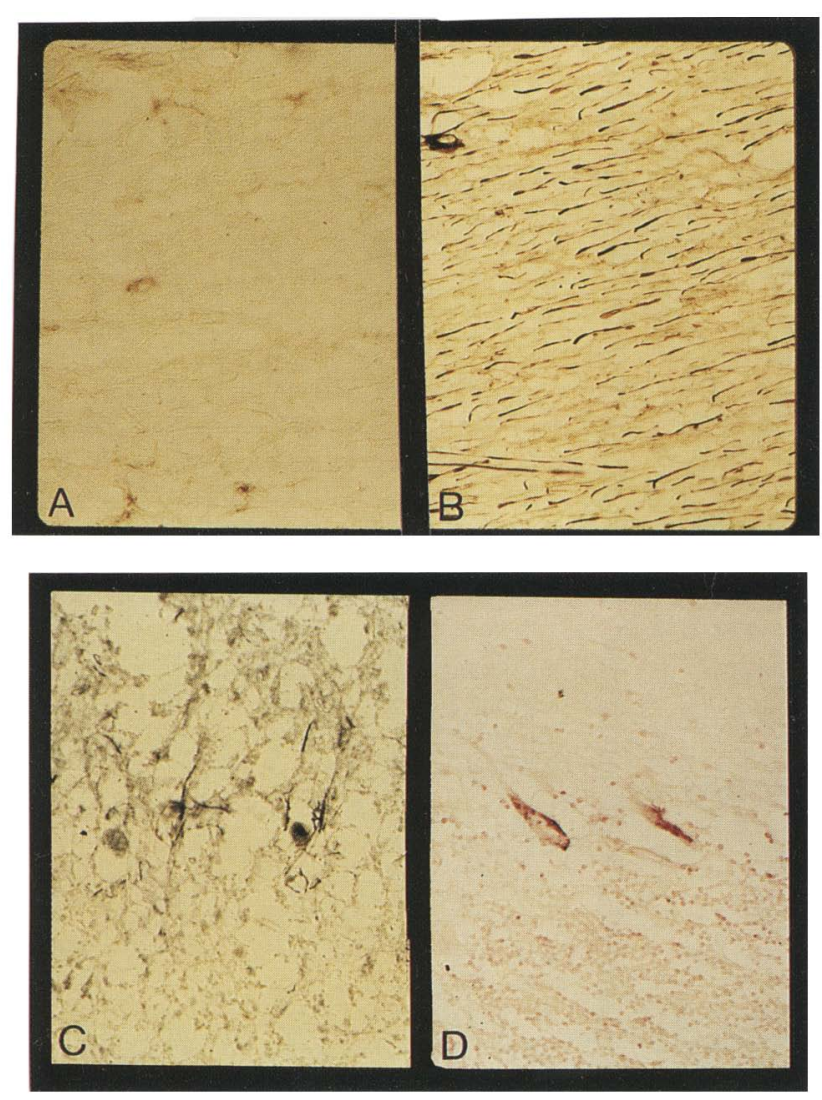

Figure 4. Immunohistochemical analysis of DCC in human neuronal tissue and in situ hybridization of DCC in human cerebellum. Frozen sections of human spinal cord taken as adjacent sections off the same block, fixed, and incubated with 10 $\mathrm{ng} / \mu \mathrm{l}$ of normal rabbit immunoglobulin $(A)$ and $2 \mathrm{ng} / \mu \mathrm{l}$ of affinity-purified anti-INDCC rabbit polyclonal antibody $(B)$. Frozen section of human cerebellar cortex $(C)$ incubated with 2 $\mathrm{ng} / \mu \mathrm{l}$ of anti-INDCC rabbit polyclonal antibody showing staining of Purkinje cells and their processes. Paraffin section of human cerebellar cortex $(D)$ hybridized with an antisense $D C C$ riboprobe demonstrating the presence of $D C C$ mRNA in Purkinje cells.

long cellular processes, indicative of neuronal-like differentiation (Greene and Tischler 1976). This morphological change is accompanied by an increase in the expression of a number of markers of neuronal differentiation. Of note, DCC mRNA and DCC protein appear to increase concomitantly with neuronal differentiation (Hedrick et al. 1992; Narayanan et al. 1992). A recent paper reports the importance of DCC expression in the induction and maintenance of the differentiated phenotype of rat PC-12 cells in response to NGF (Narayanan et al. 1992). Furthermore, persistent DCC expression was critical for maintaining the differentiated phenotype. An additional study demonstrates that PC-12 cells differentiate when overlayed on NIH-3T3 cells expressing exogenous DCC (Pierceall et al. 1994). These studies, in combination with the finding that DCC is normally expressed in mature neurons in vivo, support an important role for DCC in promoting and maintaining the differentiation of neurons.

Many light microscopic features of tumors reflect the differences between normal and neoplastic tissues with respect to differentiation. The immunohistochemical analysis presented in this paper demonstrates that DCC is expressed in a specific subset of differentiated cells in colonic mucosa. This finding raises the possibility that DCC expression in colonic epithelial cells may, as in neuronal cells, play a role in differentiation. In addition, we show that most colorectal cancers lose the expression of DCC, suggesting that expression of DCC may be incompatible with the development of these colorectal tumors. As pointed out, a subset of colorectal cancers called mucinous carcinomas maintain expression of DCC. Interestingly, mucinous carcinomas infrequently lose chromosomes $18 \mathrm{q}$ or $17 \mathrm{p}$ when compared with nonmucinous carcinomas, suggesting that they may arise through a separate genetic pathway.

In comparison to oncogenes, relatively few tumor suppressor genes have been described. The two approaches that have led to the identification of most human candidate tumor suppressor genes are linkage analysis in familial cancer syndromes and LOH studies in sporadic tumors (Stanbridge 1990). Because such approaches lead only to the identification of candidate tumor suppressor genes, mutational or functional evidence is required to actually categorize them as such. The mechanism by which DCC induces differentiation remains unclear, but a clue is provided by its sequence. The predicted amino acid sequence has homology to members of the immunoglobulin superfamily, most significantly the N-CAMs. $\mathrm{N}$-CAMs are cell-surface molecules that undergo both homophilic and heterophilic binding (Edelman 1988). Numerous studies document their importance in developmental processes (Murray et al. 1986; Reyes et al. 1991), and several studies have demonstrated that their expression is modulated in transformed cells (Greenberg et al. 1984). DCC, like these other known adhesion molecules is expressed at the cell surface, but in contrast to them DCC is expressed at relatively low levels. This leads to the speculation that the function of DCC may not be one of physically holding cells together but may be important in transmitting signals from the cell's exterior environment to its interior, thereby playing a role in controlling the differentiation of certain cell types.

\section{Materials and methods}

\section{Isolation and sequencing of DCC $c D N A$}

Several human cDNA libraries were screened with the previously isolated partial DCC cDNA (Fearon et al. 1990). Two 入gt11 libraries were used (Clontech, Palo Alto, CA), including one from adult brain and one from fetal brain. Together, these libraries encompassed $\sim 2 \times 10^{6}$ independent clones. In addition, we constructed both oligo $\{\mathrm{dT}\rangle$ and random primed fetal brain cDNA libraries in the $\lambda$ Zap (Stratagene, La Jolla, CA) phage vector which yielded an additional $2 \times 10^{6}$ clones. Each library was plated on 100 agarose plates at a density of $\sim 10,000$ 

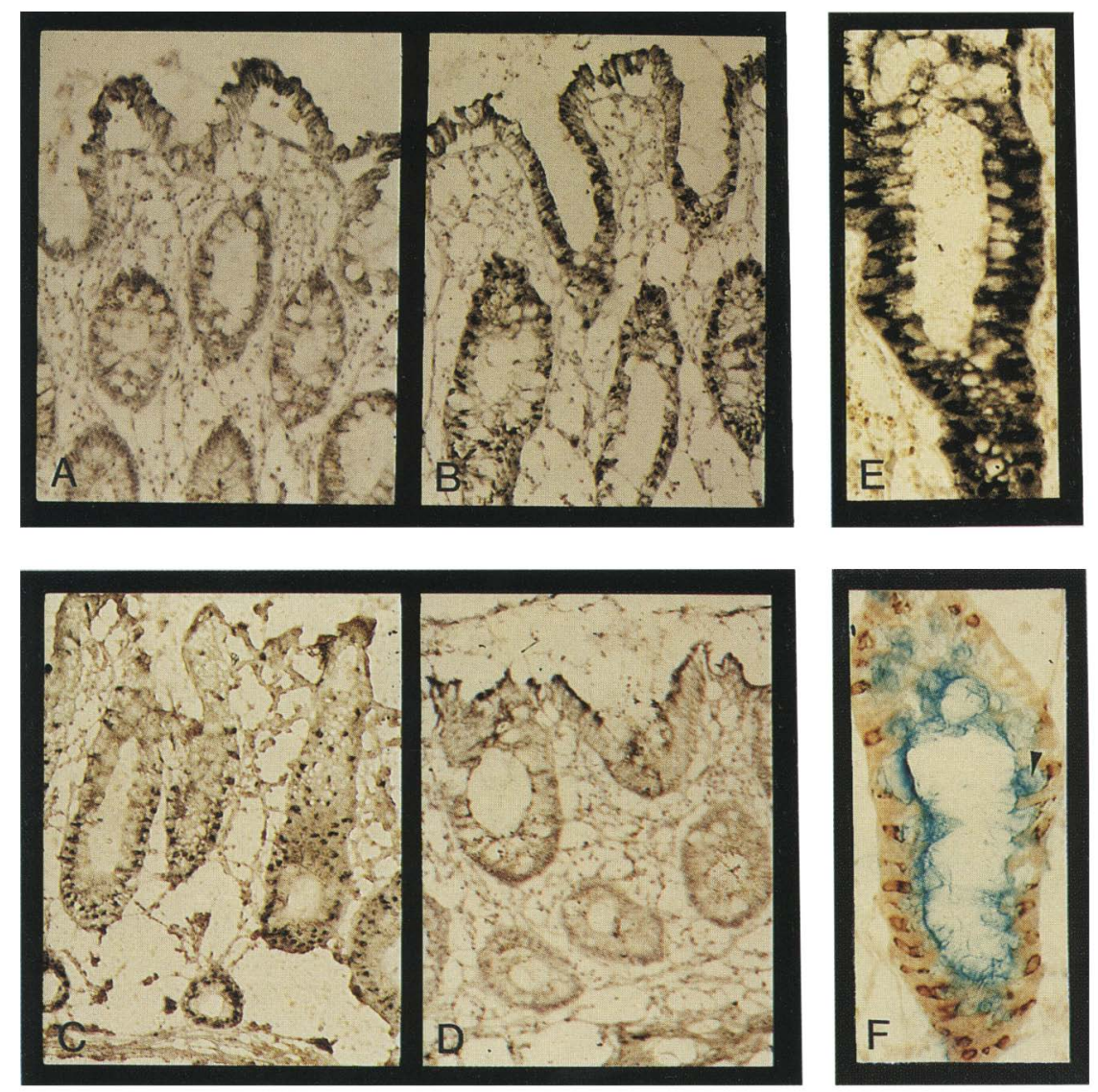

Figure 5. Immunohistochemical analysis of DCC in normal human colonic tissue. Frozen section of normal human colonic mucosa incubated with $10 \mathrm{ng} / \mu \mathrm{l}$ of normal rabbit immunoglobulin $(A)$ and $2 \mathrm{ng} /$ $\mu l$ of anti-INDCC rabbit polyclonal antibodies $(B)$ revealing DCC expression in a subset of colonic epithelial cells. To determine specificity of the DCC polyclonal antibody, the tissue was incubated with anti-INDCC antibodies in the presence of five times the molar concentration of a $\mathrm{His}_{6} \mathrm{Myc}_{\mathrm{C}}$ soluble fusion protein $(C)$ or an equal molar concentration of soluble $\mathrm{His}_{6} \mathrm{DCC}$ fusion protein $(D)$. The reactivity of the DCC antibody is competitively inhibited by the DCC fusion protein but is not affected by the Myc fusion protein. $|E|$ Immunohistochemistry of normal colonic epithelium at higher magnification, showing that DCC expression is detected only in a specific differentiated cell type. $(F)$ Immunohistochemistry was followed by a histochemical stain (AB) for mucin, showing that only the mucin-producing goblet cells of the colon (those staining blue), are positive for DCC, as indicated by the brown stain. (Note: The mucin extends over the entire surface of the colonic crypt, but intracellular mucin is limited to the goblet cells, arrowhead.) phage per plate. Filters were hybridized under standard conditions to cDNA probes labeled to high specific activity (Feinberg and Vogelstein 1983).

\section{Plasmid Constructions}

A cDNA encompassing the entire DCC-coding region (from nucleotides -15 to 4496 ) was cloned into the pBluescript (Stratagene) plasmid vector by connecting several overlapping partial cDNA clones at convenient restriction sites. The full-length $D C C$ insert was excised from pBluescript and cloned into the $X$ hol site of the eukaryotic expression vector $\mathrm{pCMVneo,}$ which uses a cytomegalovirus (CMV) promotor to drive expression of inserted sequences. In addition, the plasmid carries a neomycin (neo) resistance gene. The sequence of the DCC insert in the final expression vector was verified in its entirety. A mutant DCC expression construct was created that contained an early stop codon at position 256. The two central nucleotides from the SstII restriction site at position 189 were deleted using the $3^{\prime} \rightarrow 5^{\prime}$ exonuclease activity of the Klenow fragment of DNA polymerase I.

\section{Fusion proteins and polyclonal antibodies}

Bacterial fusion proteins were generated in Trp-E (pATH) fusion vectors using nucleotides 591-1239 and nucleotides 3309-4453 for the production of anti-EXDCC and anti-INDCC antibodies, respectively. The fusion proteins were insoluble and were isolated by sonication from bacterial inclusion bodies. The proteins were separated in preparative denaturing polyacrylamide gels, and the gel slices were homogenized with Freund's adjuvant. Rabbits were immunized by subcutaneous injection, and the resultant sera affinity purified by passage over amino-linked Sepharose columns (Pierce, Rockford, IL) linked with bacterial fusion proteins containing identical sequences of DCC in pGEMEX (Promega, Madison, WI) expression vectors. The construction of the $\mathrm{His}_{6} \mathrm{DCC}$ was done by cloning an $\sim 1.0 \mathrm{kbp} D C C$ cDNA fragment, encoding amino acids 1153-1446, into the BamHI site of pDS-MCS in-frame and downstream of the 6 histidine residues. Likewise the $\mathrm{His}_{6}$ myc was constructed by cloning an $\sim 300$-bp human myc cDNA fragment, encoding amino acids $342-439$, into the EcoRV and HindIII sites of pDSMCS. The histidine fusion proteins were purified following a 2to 3 -hr induction of the recombinant bacterial fusion proteins with $1 \mathrm{mM}$ IPTG, each 1.0-liter bacterial culture was pelleted, and the cell pellets resuspended in $6 \mathrm{M}$ guanidine, $50 \mathrm{~mm} \mathrm{NaPO}_{4}$ $(\mathrm{pH} 8.0)$. The cell lysate was cleared with a brief centrifugation step, and the cleared lysate was loaded onto a $\mathrm{Ni}^{2+}$ agarose (Quiagen) column. After extensive washing, bound proteins were eluted by a $\mathrm{pH}$ step gradient. The column fractions containing fusion proteins were dialyzed extensively against 100 $\mathrm{mm} \mathrm{NaCl}, 10 \mathrm{~mm}$ Tris (pH 7.5), and 1 mm EDTA.

\section{Immunoprecipitations}

Cells were grown as monolayers in T25 tissue culture flasks to $\sim 80 \%$ confluence. They were rinsed twice in Hank's buffered salt solution (HBSS, GIBCO, Gaithersburg, MD) and incubated for $4 \mathrm{hr}$ in complete medium containing $200 \mu \mathrm{Ci} / \mathrm{ml}$ of $\left[{ }^{35} \mathrm{~S}\right] \mathrm{me}$ - 
DCC gene product in differentiation and tumorigenesis
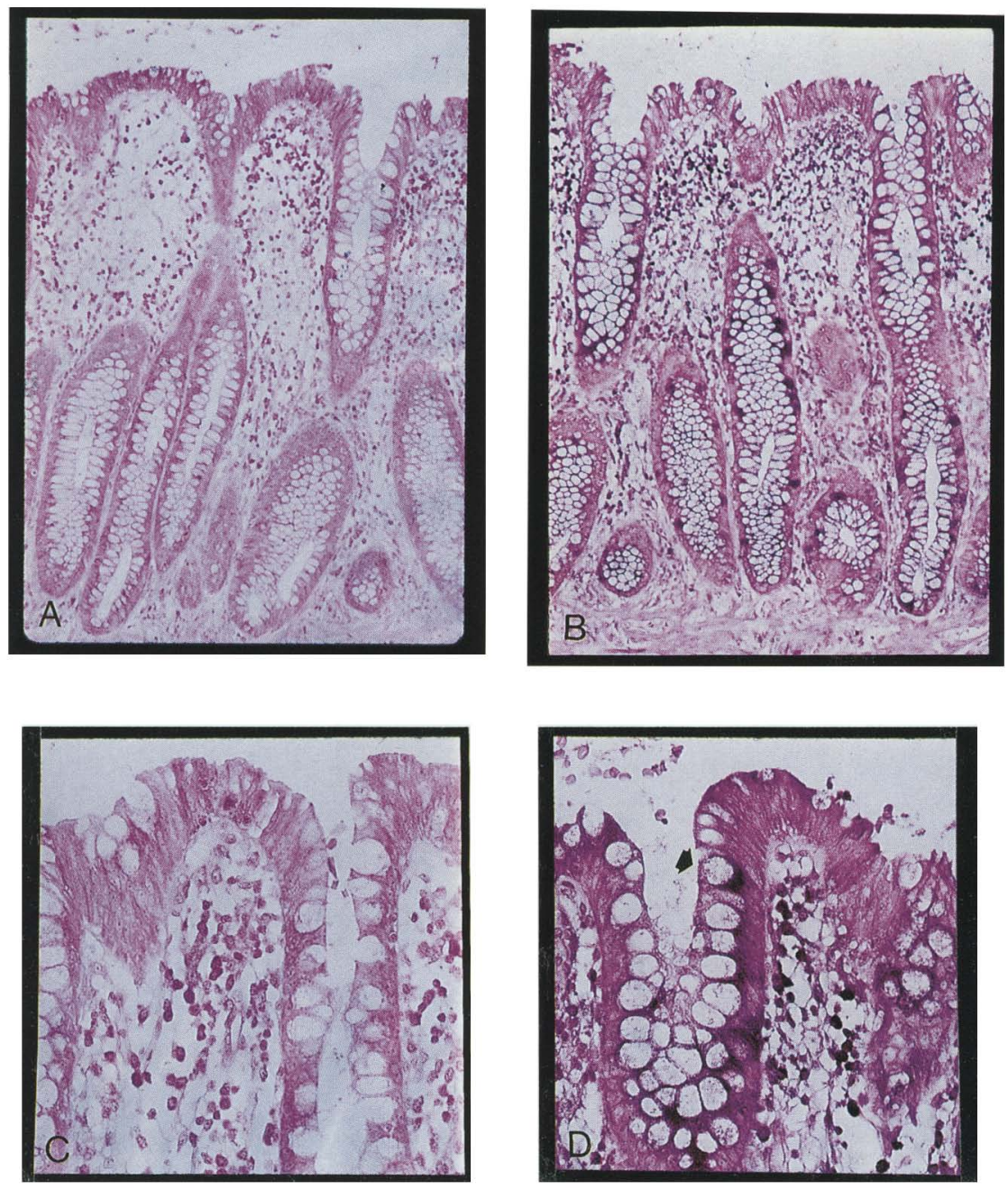

Figure 6. In situ hybridization of $D C C$ in normal colonic tissue. Sense $(A, C)$ and antisense $(B, D)$ probes were incubated with formalin-fixed paraffin-embedded tissue sections of normal colon. The low magnification $(39 \times)$ photomicrograph $(B)$ of tissue incubated with the antisense probe demonstrates increased signal intensity (dark purple staining) in the neck and base of the crypts with very little signal in the epithelium at the luminal (top) surface. This pattern correlates with the location of goblet cells within the crypts. At higher magnification $\{120 \times ; D\}$, the signal is clearly localized in goblet cells (as indicated by an arrowhead). The tissue section incubated with the sense probe, used as a control, demonstrates a lack of specific signal with the in situ hybridization procedure $(A, C)$.

thionine (ICN Translabel, Irvine, CA) for metabolic labeling. The cells were rinsed twice in HBSS, lysed in a denaturing buffer of $10 \mathrm{~mm}$ Tris (pH 7.5) and $0.5 \%$ SDS, and boiled for 10 min. The lysates were then diluted with $10 \mathrm{mM}$ Tris $(\mathrm{pH} 7.5)$, $1 \%$ deoxycholate, $1 \% \mathrm{NP}-40$, and $150 \mathrm{~mm} \mathrm{NaCl}$ to a final concentration of $0.1 \%$ SDS (RIPA). The lysates from each flask were precleared for $60 \mathrm{~min}$ at $4^{\circ} \mathrm{C}$ with $20 \mu \mathrm{l}$ of preimmune serum immobilized on $20 \mathrm{mg}$ of protein A-Sepharose (Sigma). The precleared lysates were assayed for incorporation of the translabel, and $20 \times 10^{6}$ to $80 \times 10^{6} \mathrm{cpm}$ was used for each immunoprecipitation. Affinity-purified antibody was added at a final concentration of $1-2 \mathrm{ng} / \mu \mathrm{l}$ and incubated on ice at $4^{\circ} \mathrm{C}$ for $2.5 \mathrm{hr}$. To capture the immune complex, $5 \mathrm{mg}$ of protein A-Sepharose was added to each immunoprecipitation and incubated end over end for $45 \mathrm{~min}$ at $4^{\circ} \mathrm{C}$. The bound complexes were sedimented and washed three times with RIPA. The eluted proteins were separated by electrophoresis in denaturing polyacrylamide gels. For the detection of cell-surface proteins the cells were labeled with ${ }^{125}$ I by the lactoperoxidase method as described previously (Pfaffle et al. 1988). After the labeling procedure, the immunoprecipitations were carried out as described above with the exception that only $1 \times 10^{6}$ to $2 \times 10^{6} \mathrm{cpm}$ was used in each immunoprecipitation. For the p53 immunoprecipitation, an equal mixture of two monoclonal antibodies
(Abl801 and Ab421, Oncogene Science, Cambridge, MA) was used at a final concentration of $20 \mathrm{ng} / \mu \mathrm{l}$.

\section{Immunoblotting}

Cells were grown to confluent monolayers and lysed directly in SDS-electrophoresis sample buffer (2\% SDS, $5 \%$ glycerol, $5 \%$ 2-mercaptoethanol in $0.0625 \mathrm{M}$ Tris at $\mathrm{pH} 6.8$ ). The protein concentrations of the lysates were determined by an amido blueblack assay. The proteins were fractionated on SDS-polyacrylamide gels and transferred to nitrocellulose (Schleicher \& Schuell, Keene, NH) using a semidry electroblotter (Millipore, Bedford, MA). The filters were blocked in $10 \%$ nonfat dry milk and $10 \%$ goat serum in TTBS [ $100 \mathrm{~mm}$ Tris $(\mathrm{pH} 7.5), 0.9 \% \mathrm{NaCl}$, $0.1 \%$ Tween 20 ] for $60 \mathrm{~min}$ at room temperature. Primary antibody was added to the blocking solution at a final concentration of $0.5-1.0 \mu \mathrm{g} / \mathrm{ml}$, and the filter was incubated for 2-3 hours at room temperature. The filters were washed three times with TTBS and incubated with a goat anti-rabbit ${ }^{125} \mathrm{I}$-coupled antibody $\left(4.8 \times 10^{5} \mathrm{cpm} / \mathrm{ml}\right)$ in $0.5 \%$ nonfat dry milk/TTBS. The filters were washed extensively in TTBS, and the bound antibody was detected by autoradiography. 

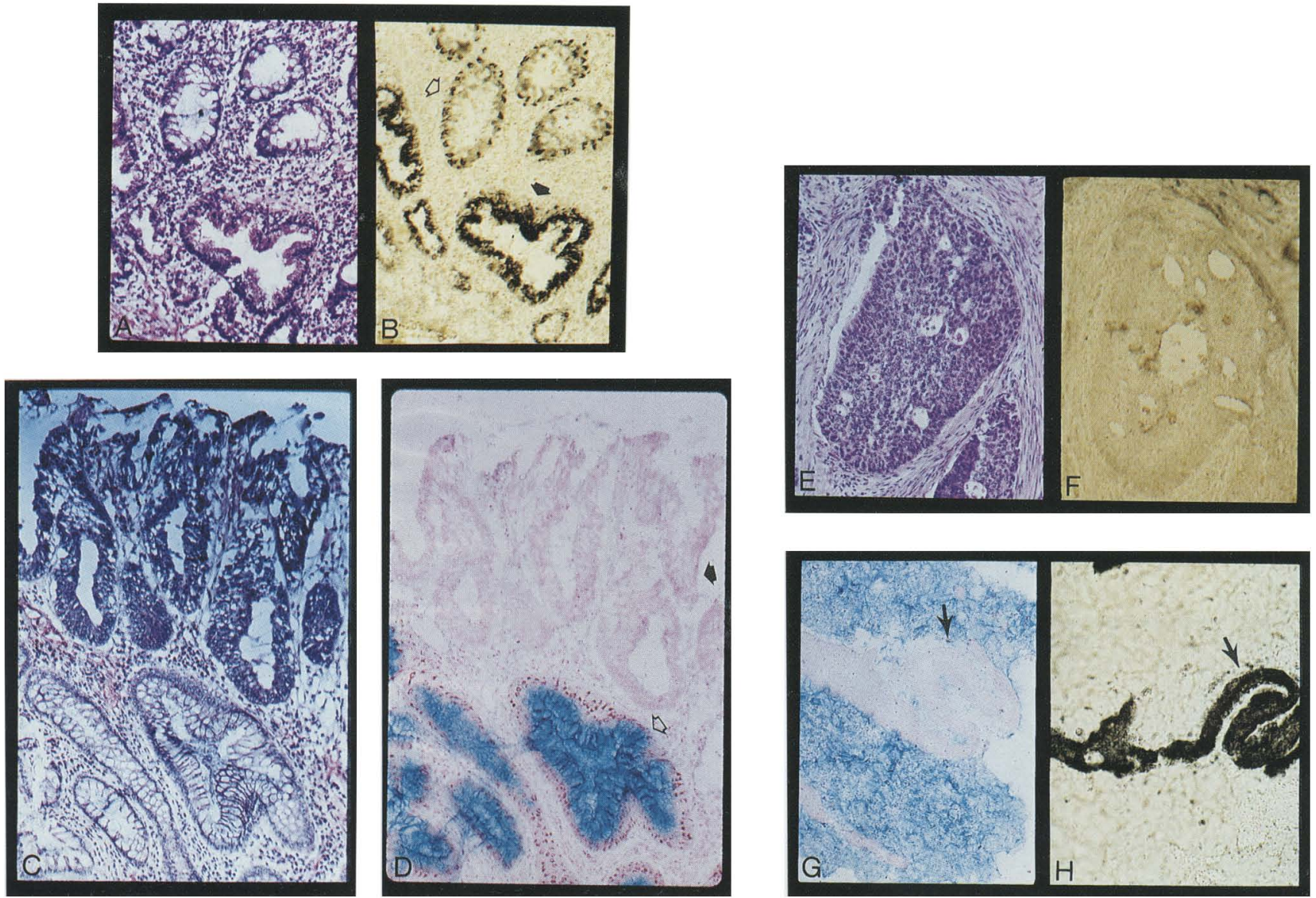

Figure 7. Immunohistochemical analysis of $D C C$ in benign and malignant tumors of the colon. All immunohistochemistry was done with the anti-INDCC polyclonal rabbit antibody. $(A)$ Frozen section of hematoxylin and eosin (H\&E)-stained hyperplastic polyp of the colon showing several normal glands (open arrow in $B$ ) and several hyperplastic glands (closed arrow in $B$ ) lined by abnormal epithelium. $(B)$ The adjacent section of the same hyperplastic polyp incubated with DCC antibody. $(C)$ H\&E-stained section of an adenomatous colonic polyp with normal glands on the bottom (open arrow in $D$ ) and adenomatous glands at the top (closed arrow in $D)$. $(D)$ The adjacent section of the same polyp stained with DCC antibody. H\&E-stained section of an invasive colorectal carcinoma $(E)$ and the adjacent section stained with DCC $(F)$. AB-stained section of a mucinous colorectal carcinoma $(G)$ and the adjacent section incubated with anti-DCC antibody $(H)$. The pink band present in the AB-stained section $(G)$ are the tumor cells (arrow) embedded in a pool of mucin (staining blue). By immunohistochemical analysis $(H)$ the pink band of tumor cells (arrow), in an adjacent section, stain an intense brown consistent with relatively high levels of DCC expression.

\section{Immunohistochemistry}

Tissue was frozen in liquid nitrogen and stored at $-80^{\circ} \mathrm{C}$. Tissue for sectioning was removed from $-80^{\circ} \mathrm{C}$ storage and embedded immediately, without thawing, in OCT compound (Miles, Elkhart, IN). Approximately $7-\mu \mathrm{m}$ sections were cut on a cyrostat and placed on treated glass slides (Fischer, Pittsburgh, PA). The tissue sections were fixed for $5 \mathrm{~min}$ in $10 \%$ buffered formalin and rinsed extensively with Dulbecco's PBS (Sigma). Endogenous peroxidase activity was blocked by incubation in $0.3 \% \mathrm{H}_{2} \mathrm{O}_{2}$ in methanol for $30 \mathrm{~min}$ at room temperature. The signal-to-noise ratio was enhanced by the antigen retrieval method (Biogenex, San Ramon, CA). The slides were placed in a humidified chamber and blocked for $30 \mathrm{~min}$ with goat serum. The sections were incubated for 2.5-3 hr at room temperature with the anti-INDCC rabbit polyclonal antibody at $2-3 \mathrm{ng} / \mu \mathrm{l}$ in goat serum. A secondary goat anti-rabbit biotinylated antibody (Pierce) followed by the Vectastain Elite (Vector Laboratories,
Burlingame, CA| was used for detection. The chromagen diaminobenzidene with nickel enhancement was used for light microscopic visualization of the signal.

\section{In situ hybridization}

RNA in situ hybridization was performed essentially as described previously (Wu et al. 1992). Five-micron sections on treated glass slides were heated to $65^{\circ} \mathrm{C}$, dewaxed in xylene and rehydrated in ethanol, then digested with proteinase $\mathrm{K}(20 \mu \mathrm{g} /$ $\mathrm{ml}$ ) for $30 \mathrm{~min}$ at $37^{\circ} \mathrm{C}$. The slides were treated with triethanolamine, acetic anhydride, and dehydrated. The riboprobes were prepared from pBluescript containing a DCC insert consisting of the cytoplasmic domain of DCC (amino acids 1104-1447). The plasmid was linearized with $\mathrm{Xbal}$ and transcribed in vitro in the presence of digoxigenin-UTP. The tissue was incubated with the riboprobes in a formamide solution $[50 \%$ formamide, 
0.1 mole/liter PIPES (pH 7.8), 0.01 mole/liter ethylenediaminetetra-acetic acid [EDTA)] in a volume to cover the section. The sections were hybridized for $6 \mathrm{hr}$ at $50^{\circ} \mathrm{C}$ and placed in $4 \times$ SSC. The sections were successively washed in $1 \times$ and $0.1 \times$ SSC and incubated in $10 \mu \mathrm{g} / \mathrm{ml}$ of RNAse $\mathrm{A}$ in $2 \times \mathrm{SSC}$ at $37^{\circ} \mathrm{C}$ for 15 min. The sections were blocked with $2 \%$ blocking agent (Boehringer Mannheim, Indianapolis, IN) followed by incubation with anti-digoxigenin antibody conjugate. The color reagent nitroblue tetrazolium salt (NBT, Kodak, Rochester, NY) was used for signal detection, and the slides were counterstained with eosin.

\section{Acknowledgments}

This work was supported by the Howard Hughes Medical Institute, the Clayton Fund, and National Institutes of Health grant CA-35494 to B.V. L.H. is a Howard Hughes Medical Institute physician research fellow and B.V. is an American Cancer Society research professor.

The publication costs of this article were defrayed in part by payment of page charges. This article must therefore be hereby marked "advertisement" in accordance with 18 USC section 1734 solely to indicate this fact.

\section{References}

Boman, B., D. Wildrick, and S. Alfaro. 1988. Chromosome 18 allele loss at the D18S6 locus in human colorectal carcinomas. Biochem. Biophys. Res. Commun. 155: 463-469.

Cho, K.R., J.D. Oliner, J.W. Simons, L. Hedrick, E.R. Fearon, A.C. Presinger, P. Hedge, G.A. Silverman, and B. Vogelstein. 1994. The DCC gene: Structural analysis and mutations in colorectal carcinomas. Genomics 19: $525-531$.

Edelman, G. 1988. Morphoregulatory molecules. Biochemistry 27: 3533-3543.

Fearon, E.R., K.R. Cho, J.M. Nigro, S.E. Kern, J.W. Simons, J.M. Ruppert, S.R. Hamilton, A.C. Preisinger, G. Thomas, K.W. Kinzler, and B. Vogelstein. 1990. Identification of a chromosome $18 \mathrm{q}$ gene that is altered in colorectal cancers. Science 247: 49-56.

Feinberg, A.P. and B. Vogelstein. 1983. A technique for radiolabeling DNA restriction endonuclease fragments to high specific activity. Anal. Biochem. 132: 6-13.

Gao, X., K. Honn, D. Grignon, W. Sakr, and Y. Chen. 1993. Frequent loss of expression and loss of heterozygosity of the putative tumor suppressor gene DCC in prostatic carcinomas. Cancer Res. 53: 2723-2727.

Greenberg, M., R. Brackenbury, and G. Edelman. 1984. Alteration of neural cell adhesion molecule (N-CAM) expression after neuronal cell transformation by Rous sarcoma virus. Proc. Natl. Acad. Sci. 81: 969-973.

Greene, L. and A. Tischler. 1976. Establishment of a noradrenergic clonal line of rat adrenal pheochromocytoma cells which respond to nerve growth factor. Proc. Natl. Acad. Sci. 73: 2424-2428.

Gu, W., J. Schneider, G. Condorelli, S. Kaushal, V. Mahdavi, and B. Nadal-Ginard. 1993. Interaction of myogenic factors and the retinoblastoma protein mediates muscle cell commitment and differentiation. Cell 72: 309-324.

Hedrick, L., K. Cho, J. Boyd, J. Risinger, and B. Vogelstein. 1992. DCC: A tumor suppressor gene expressed on the cell surface. Cold Spring Harbor Symp. Quant. Biolo. 57: 345-351.

Hohne, M.W., M. Halatsch, G.F. Kahl, and R.J. Weinel. 1992. Frequent loss of expression of the potential tumor suppressor gene DCC in ductal pancreatic adenocarcinoma. Cancer
Res. 52: 2616-2619.

Klingelhutz, A.J., P.P. Smith, L.R. Garrett, and J.K. McDougall. 1993. Alteration of the DCC tumor-suppressor gene in tumorigenic HPV-18 immortalized human keratinocytes transformed by nitrosomethylurea. Oncogene 8: 95-99.

Marshall, C. 1991. Tumor suppressor genes. Cell 64: 313-326.

Monpezat, J., O. Delattre, A. Bernard, D. Grunwald, Y. Remvikos, M. Muleris, R. Salmon, G. Frelat, B. Dutrillaux, and G. Thoams. 1988. Loss of alleles on chromosome 18 and on the short arm of chromosome 17 in polyploid colorectal carcinomas. Int. I. Cancer 41: 404-408.

Muleris, M., R. Salmon, A. Dutrillaux, P. Vielh, B. Zafrani, J. Girodet, and B. Dutrillaux. 1987. Characteristic chromosomal imbalances in 18 near-diploid colorectal tumors. Cancer Genet. Cytogenet. 29: 289-301.

Murray, B., G. Owens, E. Prediger, K. Crossin, B. Cunningham, and G. Edelman. 1986. Cell surface modulation of the neural cell adhesion molecule resulting from alternative mRNA splicing in a tissue-specific developmental sequence. J. Cell Biol. 103: 1431-1439.

Narayanan, R., K.G. Lawlor, R.Q.J. Schaapveld, K.R. Cho, B. Vogelstein, P.B.V. Tran, M.P. Osborne, and N.T. Telang. 1992. Antisense RNA to the putative tumor-suppressor gene DCC transforms Rat-1 fibroblasts. Oncogene 7: 553-561.

Patthy, L. 1990. Homology of a domain of the growth hormone/ prolactin receptor family with type III modules of fibronectin. Cell 61: 13-14.

Peehl, M. and E. Stanbridge. 1982. The role of differentiation in the suppression of tumorigenicity in human cell hybrids. Int. J. Cancer 30: 113-120.

Pfaffle, M., F. Ruggiero, H. Hofmann, M. Fernandez, O. Selmin, Y. Yamada, R. Garrone, and K. von der Mark. 1988. Biosynthesis, secretion and extracellular localization of anchorin CII, a collagen-binding protein of the calpactin family. EMBO J. 7: 2335-2342.

Pierceall, W.E., K.R. Cho, R.H. Getzenberg, M.A. Reale, L. Hedrick, B. Vogelstein, and E.R. Fearon. 1994. The deleted in colorectal cancer (DCC) tumor suppressor gene product stimulates neurite outgrowth in rat $\mathrm{PC} 12$ pheochromocytoma cells. J. Cell Biol. 124: 1017-1027.

Porfiri, E., L. Secker-Walker, A. Hoffbrand, and J. Hancock. 1993. DCC tumor suppressor gene is inactivated in hematologic malignancies showing monosomy 18. Blood 81: 26962701.

Reyes, A., S. Small, and R. Akeson. 1991. At least 27 alternatively spliced forms of the neural cell adhesion molecule mRNA are expressed during rat heart development. Mol. Cell. Biol. 11: 1654-1661.

Stanbridge, E. 1990. Human tumor suppressor genes. Annu. Rev. Genet. 24: 615-657.

Uchino, S., H. Tsuda, M. Noguchi, J. Yokota, M. Terada, T. Saito, M. Kobayashi, T. Sugimura, and S. Hirohashi. 1992. Frequent loss of heterozygosity at the DCC locus in gastric cancer. Cancer Res. 52: 3099-3102.

Vogelstein, B., E. Fearon, S. Hamilton, S. Kern, A. Preisinger, M. Leppert, Y. Nakamura, R. White, A. Smits, and J. Bos. 1988. Genetic alterations during colorectal-tumor development. N. Engl. J. Med. 319: 525-532.

Wu, T., W. Lee, M. Pizzorno, W. Au, Y. Chan, R. Hruban, G. Hutchins, and G. Hayward. 1992. Localization of the human cytomegalovirus $2.7-\mathrm{kb}$ major early B-gene transcripts by RNA in situ hybridization in permissive and nonpermissive infections. Am. J. Pathol. 141: 1247-1254. 


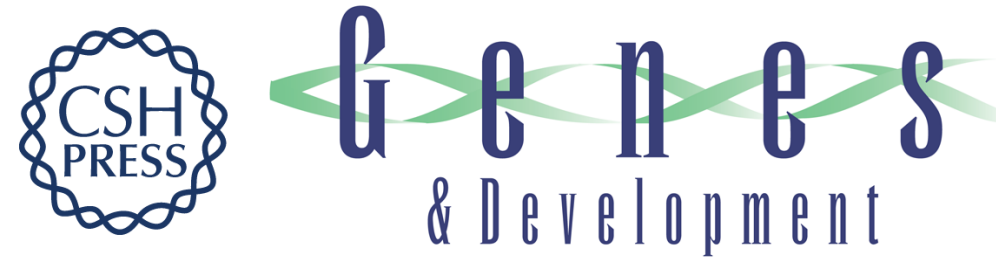

\section{The DCC gene product in cellular differentiation and colorectal tumorigenesis.}

L Hedrick, K R Cho, E R Fearon, et al.

Genes Dev. 1994, 8:

Access the most recent version at doi:10.1101/gad.8.10.1174

References This article cites 27 articles, 10 of which can be accessed free at:

http://genesdev.cshlp.org/content/8/10/1174.full.html\#ref-list-1

License

Email Alerting

Service

Receive free email alerts when new articles cite this article - sign up in the box at the top right corner of the article or click here.

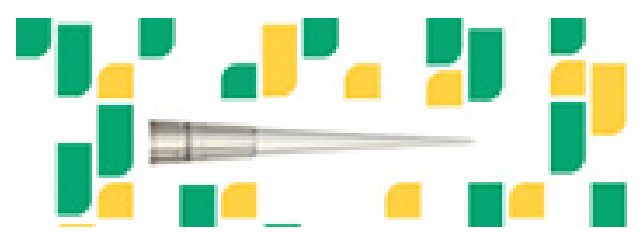

Focused on your science.

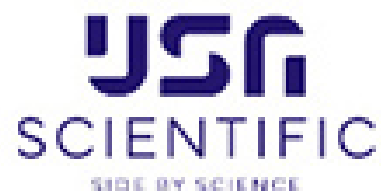

Copyright (c) Cold Spring Harbor Laboratory Press 